\title{
CLINICAL EVALUATION OF THE EFFICACY OF BIORESORBABLE MEMBRANE (POLYGLACTIN 910) IN THE TREATMENT OF MILLERS' CLASS II GINGIVAL RECESSION
}

\author{
Manik Sharma $^{1}$, Anuj Wangoo ${ }^{2}$, Manmeet Singh Gulati ${ }^{3}$, Bhawna Slathia ${ }^{4}$, Bhanu Kotwal ${ }^{5}$, Vineet Kotwal ${ }^{6}$ \\ ${ }^{1}$ Associate Professor Department of Periodontics, IGG Dental College, Jammu, India \\ ${ }^{2}$ Professor and Head, Department of Prosthodontics, JCD Dental College, Haryana, India \\ ${ }^{3}$ Head, Department of Prosthodontics, DeshBhagat Dental College, Punjab, India \\ ${ }^{4}$ House Surgeon IGG Dental College, Jammu, India \\ ${ }^{5}$ Registrar, Department of Periodontics, IGG Dental College, Jammu, India \\ ${ }^{6}$ Assistant Professor, Department of Periodontics, IGG Dental College, Jammu, India
}

\begin{abstract}
-
ABSTRACT

Objective: The aim of the study was to determine the clinical outcome when polyglactin 910 membrane was used to treat 30 patients with isolated buccal millers class II gingival recessions. Materials and Method: Thirty subjects were selected with a chief complaint of hypersensitivity or denuded roots; all were willing to participate in the clinical study. Inclusion criteria were the presence of $4 \mathrm{~mm}$ or more of buccal millers class II gingival recession, a lack of contraindications for periodontal surgery. Results: The mean reduction in clinical recession from baseline to 6 months postoperatively was $2.47 \pm 0.86 \mathrm{~mm}$, i.e, $54 \%$, which was statistically significant. There was a definite reduction in Pocket Depth, from a mean at baseline of $1.53 \pm$ $0.63 \mathrm{~mm}$ to a mean of $1.07 \pm 0.26 \mathrm{~mm}$ at 6 months. Conclusion: The use of GTR is a suitable alternative to the use of patient's own palatal masticatory mucosa. Polyglactin 910 as a GTR resorbable membrane gives the clinician another tool that provides acceptable root coverage.
\end{abstract}

Keywords: GTR, Recession, Pocket, Periodontal Surgery

\section{INTRODUCTION}

Gingival recession is a common manifestation in most populations. Gingival recession is clinically manifested by an apical displacement of the gingival tissues, leading to root surface exposure. Coverage of denuded roots has become one of the most challenging procedures in periodontal plastic surgery.

Esthetics represents an inseparable part of today's oral therapy. Periodontal plastic surgery procedures aimed at coverage of exposed root surfaces have evolved into routine treatment modalities. The main indications for root coverage procedures are esthetic concerns, root hypersensitivity, prevention or management of root caries and cervical abrasion, enhancement of restorative outcomes, and facilitation of plaque control efforts. The goal of any therapeutic intervention aimed at root coverage should be to restore the tissue margin at the cementoenamel junction (CEJ) and to achieve an attachment of the tissues to the root surface so that a normal healthy gingival sulcus with no bleeding on probing and a minimal probing depth is present. ${ }^{1}$

Recently, patients have become more conscious of dental esthetics and accordingly have been demanding precision treatment of their exposed root surfaces. Various surgical options, such as a laterally positioned flap, free gingival 
grafting, and connective tissue grafting in combination with a pedicle graft, have been tried with reasonable success. ${ }^{2}$ Although soft tissue auto- grafts are predictable when the proper technique is used, they are not without their drawbacks, which include the creation of an additional surgical wound and additional discomfort to the patient.

The search for the appropriate root coverage technique has taken many different approaches. Various surgical options with predictable outcomes are available. In this clinical study, patients were treated using polyglactin 910 (Vicryl mesh) and a coronally positioned flap. Clinical parameters for 30 patients were recorded immediately prior to surgery and after a minimum of 6 months. Postoperatively, significant root coverage, reductions in probing depths, gains in clinical attachment levels, and highly significant increases in the width of keratinized gingiva were observed. The final esthetics, both color match and tissue contours, were acceptable to both the patients and the clinicians.

A technique pioneered by Nyman et $\mathrm{al},{ }^{3}$ which was later named guided tissue regeneration (GTR) by Gottlow et $\mathrm{al}^{4}$, has been added to the arsenal of periodontal procedures. The principles of the GTR technique, initially used mainly to treat infrabony and furcation defects, have been adapted for root coverage procedures. GTR procedures have employed both nonabsorbable and bioresorbable membranes as barriers. The obvious disadvantage of nonabsorbable membrane is the need for a re-entry procedure to remove the material, resulting in great inconvenience and extra cost to the patients. ${ }^{5}$ Moreover, the probability of surgical complications such as exposure and infection is greater with nonabsorbable membranes. These negative factors have instigated research for the development of bioresorbable devices made of collagen, polyglycolic acid, and polylactic acid, which would eliminate the second surgical procedure. ${ }^{6}$ One such bioresorbable barrier is polyglactin 910 (Ethicon, Johnson \& Johnson), which is prepared from a copolymer of glycolide and lactide in a ratio of 9 to 1 ; it is biocompatible, inexpensive, and readily available and has been successfully tried for the management of buccal gingival recessions. The material is available as sterile synthetic bioresorbableVicryl knitted mesh sealed within foil in an inert atmosphere.

The present study was designed to assess the effectiveness and predictability of this absorbable membrane in the treatment of human recession defects with a single-step surgical procedure. The aim of the study was to determine the clinical outcome when polyglactin 910 membrane was used to treat 30 patients with isolated buccal miller's class II gingival recessions.

\section{MATERIALS AND METHOD}

\section{Study design}

The subjects for the study were selected from those attending the out-patient Department of Periodontics at IGG Dental College \& Hospital, Jammu (J\&K) India. Thirty subjects were selected with a chief complaint of hypersensitivity or denuded roots; all were willing to participate in the clinical study. Inclusion criteria were the presence of $4 \mathrm{~mm}$ or more of miller's class II buccalgingival recession, a lack of contraindications for periodontal surgery, commitment to a longer- term maintenance program, and the ability to attend recall appointments. Smokers and patients with other habits, including the chewing of pan, tobacco, or betel nut, were excluded from the study.

Following selection, all patients received therapy consisting of oral hygiene instructions and modifications to ensure effective and atraumatic plaque control measures, scaling, selective root planing, and polishing.

\section{Clinical parameters}

Clinical parameters were recorded immediately prior to surgery and again after a minimum of 6 months postoperatively and included the following assessments (Figure $1 \mathrm{a}$ ): 


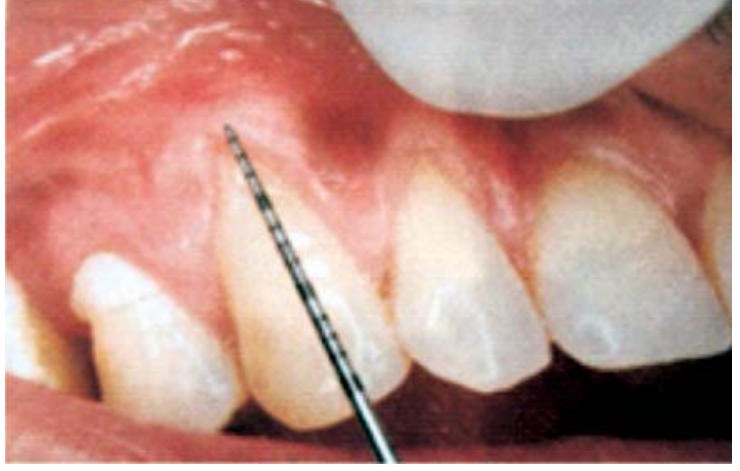

Figure 1a: Tooth no. 13, Pre-Surgical $4.0 \mathrm{~mm}$ of buccal gingival recession

- ClinicalGingival recession (CR): measured as the distance from CEJ to the gingival margin at the midbuccal level

- Probing depth(PD): measured from the most apical position of the gingival margin at the midbuccal surface of the tooth

- Clinical attachment level (CAL): measured as a distance from the fixed point that is Cemento enamel junction to the base of the pocket.

- Width of keratinized gingiva(KT): measured as the distance from the most apical position of the gingival margin to the mucogingival border at the buccal tooth surface

All clinical measurements were recorded using a calibrated University of North Carolina periodontal probe with a millimeter scale.

\section{Surgical procedure}

The surgical procedure was identical in all the patients. Patients rinsed preoperatively with $0.2 \%$ chlorhexidine mouthwash (Clohex, Group Pharmaceuticals), and local anesthesia using lignocaine hydrochloride $2 \%$ with adrenaline was given.

Primary incisions were made in mesial and distal directions from the CEJ upto $1 \mathrm{~mm}$ past the proximal line angle of the adjacent teeth, leaving the interdental papillae intact. A sulcular incision was made on the buccal aspect of the involved tooth. Two oblique releasing incisions on the mesial and distal sides were made so that trapezoidal full and split- thickness flaps could be raised without involving the adjacent papillae.

The full-thickness portion of the flap was limited to the extent of crest of the alveolar bone. The continuous partial-thickness portion extended apically into the vestibulum so that the flap could be easily repositioned as far coronally as needed. The buccal part of the papillae was de-epithelialized with a Kirkland knife to act as a connective tissue recipient site (Figure 1b) for the coronally advanced repositioned flap.

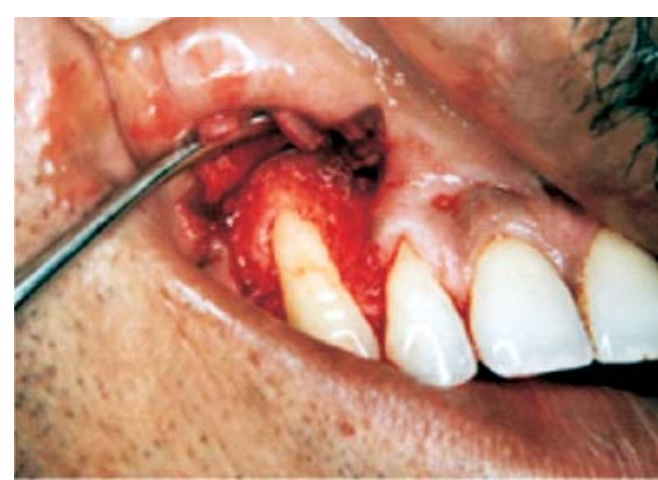

Figure 1b. Tooth no. 13, Pre-Surgical extent of recession visible after Flap reflection

The exposed root surface was cleaned, debrided, and reduced in convexity by means of curettes and burs to obtain a flattened or concave profile. A polyglactin 910 membrane was trimmed and placed to cover the bony recession defect extending from the CEJ to cover the adjacent bone mesially, distally, and apically by a few millimeters. After the membrane was secured using 5-0 Vicryl sutures (Figure $1 \mathrm{c})$, the buccal flap was coronally repositioned to cover

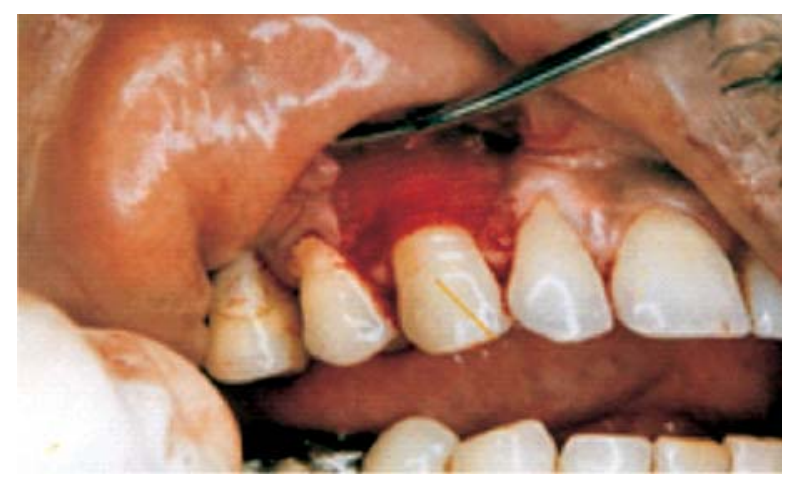

Figure 1c. Tooth no. 13, Membrane placement at level of CEJ 
the membrane and retained with nonabsorbable 4-0 braided silk sutures (Ethicon) without tension, by means of interdental interrupted sutures. No periodontal pack was given (Figure 1d).

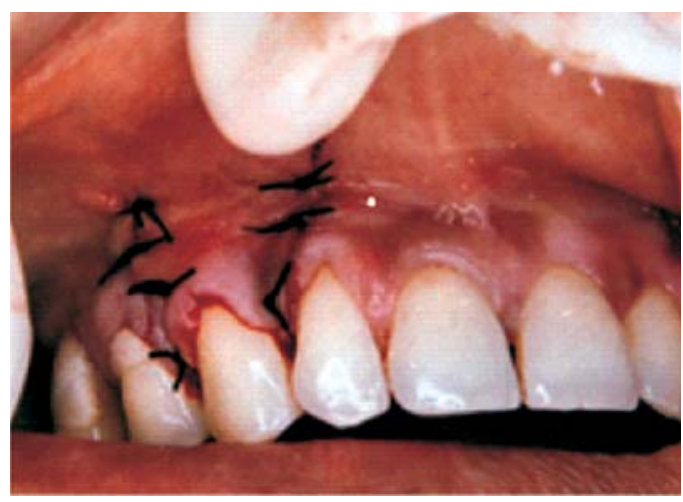

Figure 1d. Tooth no. 13, Flap coronally repositioned and sutured into place

\section{Postoperative management and care}

Patients were given both verbal and written instructions about postoperative care for the operative site; they were advised to rinse with $0.2 \%$ chlorhexidinegluconate solution twice daily and to refrain from all mechanical plaque control in and around the surgical area for 4 to 6 weeks.

Neither probing nor subgingival instrumentation was carried out during the first 3 months after surgery. Clinical parameters were evaluated and photographs were taken at 6 months postoperatively (Figure 1e).

Prescribed medications included a nonsteroidal anti-inflammatory agent for postoperative discomfort and doxycycline hyclate (200mg the day of surgery and

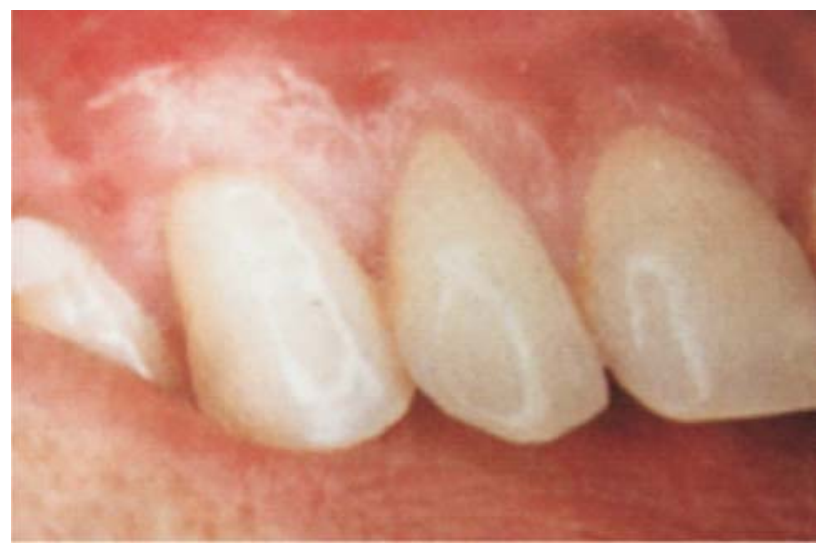

Figure 1e. Tooth no. 13, Post operative healing at 24 weeks
$100 \mathrm{mg}$ per day for the next 8 days). Sutures were removed after 10 days, and patients were recalled weekly for the next 6 weeks, followed by evaluation every 2 weeks for another 8 weeks. Professional tooth cleaning and polishing of the treated teeth were performed at each visit as needed.

\section{STATISTICALANALYSIS}

The study evaluated the efficacy of a bioresorbable membrane (polyglactin 910) in treating buccal marginal recession. Thirty subjects with an age range of 25 to 60 years participated in the study. A total of 30 buccal gingival recession sites were treated (14 in the maxilla and 16 in the mandible). All 30 patients who were enrolled in the study returned for scheduled maintenance and postoperative evaluation at 6 months. The statistical analysis was performed using the Student t-test for paired observations. Means and standard deviations were calculated for each variable and examination interval.

The patients returned for scheduled maintenance and postoperative evaluation after 6 months. The statistical analyses were performed using the Student t-test for paired observations. Means and standard deviations were calculated for each variable and at every examination interval.

\section{RESULTS AND DISCUSSION}

Amarante ES et $\mathrm{al}^{9}$, Caton Jet $\mathrm{al}^{13}$, and Tinti $\mathrm{C}$ et $\mathrm{al}^{14}$ reported a significant reduction in PD at 6 months postoperatively at sites treated with bioresorbable membranes which falls in the similar range of pocket depth reduction values in the thirty cases of this study.

The significant mean CAL gain by 6 months postoperatively was $2.96 \pm 1.03 \mathrm{~mm}(47 \%)$. This gain is comparable with other GTR studies and mucogingival surgeries. The CAL gain observed in GTR studies falls between 2.84 and $5.12 \mathrm{~mm}$, as reported by Tinti et al, ${ }^{15}$ Roccuzzo et al, ${ }^{16}$ Pini Prato et al, ${ }^{17}$ and Waterman. ${ }^{14}$

The mean increase in width of KT was $1.20 \pm$ $0.66 \mathrm{~mm}$ at 6 months after surgery. Most of the studies related to GTR have reported similar values. ${ }^{15,17,19}$ Although this increase was not as pronounced as with free gingival grafting, it was clinically significant. This phenomenon has been attributed to the capacity of the tissue regenerated from periodontal ligament cells to 
induce keratinization and to the postoperative regression of the mucogingival junction toward its genetically predetermined location. ${ }^{20}$ In the present study, no grafting material was used below the membrane. As was reported by Duval et $a 1,{ }^{21}$ the addition of demineralized freeze-dried bone allograft (DFDBA) resulted in lesser root coverage as compared to control (without DFDBA). They believed that this might be a result of difficulty in passive coronal repositioning of the flap over the membrane and graft. ${ }^{21}$ The rigid fixation of the gingival margins introduced with the present coronally anchored suturing technique minimizes micromotion of the regenerative site. ${ }^{22}$

The improvement in all the clinical parameters and achievement of acceptable root coverage justifies the use of this material in GTR procedures and avoids the drawbacks associated with non-resorbable barriers and conventional mucogingival surgeries.

\section{CONCLUSION}

Soft tissue maintenance is the primary line of defense in protecting the tissue from bacterial infection. The use of GTR is a suitable alternative to the use of patient's own palatal masticatory mucosa. Polyglactin 910 as a GTR resorbable membrane gives the clinician another tool that provides acceptable root coverage. The added advantages are a single surgical site, reduced surgical time, a gain in KT, and a potential for regeneration of a new attachment apparatus. ${ }^{23}$

This material holds promise for further studies to evaluate its clinical suitability as a graft material. Evaluation of this material with larger sample sizes and longer time periods would elicit more clear-cut results in this regard.

\section{REFERENCES}

1. Miller PD. Regenerative and reconstructive periodontal plastic surgery: Mucogingival surgery. Dent Clin North Am. 1988; 32:287-306.

2. Bahat AO, Handeisman M. Periodontal reconstructive flaps: Classification and surgical considerations, lnt J Periodontics Restorative Dent. 1991; 11:481— 487.

3. Nyman S, Gottlow J, Karring T, Lindhe J. The regenerative potential of the periodontal ligament. An experimental study in the monkey. J Clin Periodontol. 1982;9:257-265.
4. Gottlow J, Nyman S, Lindhe J, Karring T, Wennstrom J. New attachment formation in the human periodontium by guided tissue regeneration: Case report. J Clin Periodontol. 1986;13(6):604-616.

5. Urbani G, Graziani A, Lombardo G, Carton JA. Clinical results with exposed polyglactin 910 resorbable membranes for guided tissue regeneration. Int J Periodontics Restorative Dent. 1997; 17:41-51.

6. Greenstain G, CatonJG. Biodegradable barriers and guided tissue regeneration. Periodontol 2000. 1993; 1:36- 45 .

7. Doge JR, Greenwell H, Drisko C, Wittwer JW, Yancey.1, Rebitshi G. Improved bone regeneration and root coverage using a resorbable membrane within physically assisted cell migration and DFDBA. Intl Periodontics Restorative Dent. 2000;20:399-412.

8. Weng D, Hurzeler MB, Quinones CR, Pechstad B, Mota L, Caffesse RG. Healing pattern in recession defects treated with ePTFE membranes and with free connective tissue graft. A histologic and histometric study in the beagle dog. .JClinPeriodontol. 1998;25:238-245.

9. Amarante ES, Leknes KN, Skaviand J, Lie T. Coronally positioned flap procedures with or without a bioabsorbable membrane in treatment of human gingival recession. $\mathrm{J}$ Periodontol. 2000; 71:989—998.

10. Rachlin G, Koubi G, Dejou J, Franquin JC. The use of a resorbable membrane in mucogingival surgery. Case series. J Periodontol. 1996;67:621-626.

11. DE Sanctis M, Zucchelli G. Guided tissue regeneration with resorbable barrier membrane (Vicryl) for the management of buccal recession: A case report. Int J Periodontics Restorative Dent. 1996; 16:435-441.

12. Harris RJ. Comparison of two root coverage techniques: Guided tissue regeneration with a bio absorbable matrix style membrane versus a connective tissue graft combined with a coronally positioned pedicle graft without vertical incisions. Result of a series of consecutive cases. J Periodontol. 1998; 69:1426-1434.

13. Caton J, Greenstein G, Zappa U. Synthetic bioabsorbable barrier for regeneration in human periodontal defects. J Periodontol. 1994:65:1037-1045.

14. Waterman CA. Guided tissue regeneration using a bioabsorbable membranes in the treatment of human buccal recession. A re-entry study. J Periodontol. 1997; 68:982—989.

15. Tinti C, Vincenzi G, Cortellini P, Pini Prato G, Clauser C. Guided tissue regeneration in the treatment of human facial recession. A 12-case report. J Periodontol. 1992;63:554—560. 
16. Roccuzzo M, Lungo M, Corrente G, Gandolfo S. Comparative study of a bioresorbable and a non-resorbable membrane in the treatment of human buccal gingival recession. J Periodontol. 1996; 67:7-14.

17. Pini Prato G, Tinti C, Vincenzi G, Magnani C, Cortellini P, Clauser C. Guided tissue regeneration versus mucogingival surgery in the treatment of human buccal gingival recession. $\mathrm{J}$ Periodontol. 1992; 63:919-928.

18. Trombelli L, Schincaglia G, Checchi L, Calura G. Combined guided tissue regeneration, root conditioning and fibrinfibronectin system application in the treatment of gingival recession. A 15-case report. J Periodontol. 1994; 65: 796-803.

19. Harris RI. Comparison of two root coverage techniques: Guided tissue regeneration with a bioabsorbable matrix style membrane versus a connective tissue graft combined with a coronally positioned pedicle graft without vertical incisions. Result of a series of consecutive cases. J Periodontol. 1998; 69:1426-1434.
20. Pini Prato G, ClauserC, Cortellini P, Tinti C, Vincenzi G, Pagliaro U. Guided tissue regeneration versus mucogingival surgery in the treatment of human buccal recessions. A 4-year follow-up study. J Periodontol. 1996;67:1216-1223.

21. Duval BT, Maynard IG,Gunsolley JC, Waldrop TC. Treatment of human mucogingival defects utilizing bioabsorbable membrane with and without a demineralised freeze-dried bone allograft. J Periodontol. 2000; 71:1687-1692.

22. Zadeh HH. Minimally invasive treatment of maxillary anterior gingival recession defects by vestibular incision subperiosteal tunnel access and platelet-derived growth factor BB. Int J Periodontics Restorative Dent. 2011;31:653-60.

23. Oates TW, Robinson M, Gunsolley JC. Surgical therapies for the treatment of gingival recession. A systematic review. Ann Periodontol.2003; 8(1):303-20. 